EREM 74/4

Journal of Environmental Research, Engineering and Management Vol. 74 / No. 4 / 2018 pp. 60-65 DOI 10.5755/j01.erem.74.4.21103 (c) Kaunas University of Technology
Influence of Silver and Selenium Nanoparticles on Mesenchymal Stromal Cells

Received 2018/07

Accepted after revision 2018/11

\title{
Influence of Silver and
}

\section{Selenium Nanoparticles on} Mesenchymal Stromal Cells

\section{Kuzmenko V.V., Stoynova A.M., Stanishevskaya I.E., Stanishevskiy Ya.M., Vasilenko I.A.} Peoples' Friendship University of Russia (RUDN University), 6 Miklukho-Maklaya Street, Moscow, 117198, Russian Federation

Corresponding author: kuzmenko.valeria@gmail.com Kuzmenko V.V., Peoples' Friendship University of Russia (RUDN University) 6 Miklukho-Maklaya Street, Moscow, 117198, Russian Federation

Silver consisting drugs are used in the prevention and treatment of bacterial and viral diseases. Selenium consisting drugs is used as antioxidant and antitumor preparations in pharmaceutics. Biological activity and toxicity determine the dose and form of these elements. It means that the particle size reduction increases efficiency. Nanoparticles were obtained by chemical methods. The suspensions were analyzed using the cross-correlation method of photons. It was proved that the increase of concentration of silver nanoparticles $20-45 \mathrm{~nm}$ are observed of morphological changes and apoptosis of cells in the cell culture. Selenium particles with a minimum size of $500 \mathrm{~nm}$ and a minimum dose of $0.005 \mathrm{mg} / \mathrm{ml}$ cause a toxic effect: a decrease in survival rate, single morphology changes.

Keywords: nanotoxicity, influence of nanoparticles, toxicity of nanoparticles, mesenchymal stem cell.

\section{Introduction}

Currently, nanoparticles (NP) are widely used in the development of drugs and biologically active additives [Jones S.A., 2004; Elechiguerra et al, 2005].

However, the accelerating production and introduction into commercial products of AgNPs have consequence to release into the environment and affect the environmental concerns and humans health. There are many questions to be understood the positive and negative effects of AgNPs. To elucidate the environmental transformation of AgNPs, the behavior of AgNPs should be thoroughly monitored in complex environmental relevant conditions [Liu et al, 2015; McGillicuddy et al, 2017]. 
NP successfully transported through the barriers of the body, reached various populations of cells of organs and tissues, including mesenchymal stromal cells (MSC)[Schwartz S., 2009]. The fissions errors of MSCs are fundamental in the cancer development [Wang, 2013]. There are data about toxic effect of NP, the ability to exert negative effects at the cellular level, leading to metabolic disorders, genetic changes, apoptosis and necrosis in the current scientific literature [Foldbjerg et al, 2009]. The aim of this work is to determine the effect of silver and selenium nanoparticles on the morphology and survivability of MSC cultures.

Currently, silver NP are widely used in medicine, pharmacology, as hygienic and packaging, BADS and other applications. Silver NP is used in bone and cartilage transplants due to its antimicrobial and antiviral properties. The studies focus on the study of cytotoxicity, genotoxicity and cell differentiation, depending on the particle size, their concentration and exposure time [Tran et al, 1997].

Selenium hold the potential to bioaccumulation and cryptotoxic to ecosystems. Though selenium is found naturally in the earth's crust, especially in carbonate rocks and volcanic and sedimentary soils, about $40 \%$ of the selenium emissions to atmospheric and aquatic environments are caused by various industrial activities such as mining-related operations [Tan et al, 2016]. The role of selenium compounds have been extensively studied as antioxidants, in the prevention and treatment of hepatitis and various types of tumors [Yu et al, 1997]. The dose and form of selenium are important factors determining its biological activity, toxicity and antitumor activity [Beheshti et al, 2013]. Studies show that the action of selenium extends to several types of tumors, including the breast, lung, prostate and colon. New results of influence of a number of inorganic NP on the viability of mesenchymal precursors were obtained in this research.

\section{Methods}

\section{Synthesis and analysis of the nanoparticles}

A suspension of silver nanoparticles was prepared by the reduction of tannin salts of $\mathrm{AgNO} 3$ or $\mathrm{Ag} 2 \mathrm{SO} 4$ in the presence of a buffer solution (LenReaktiv, Russia). Selenium nanoparticles were synthesized in reaction of selenious acid (LenReactiv, Russia) and ascorbic acid (Biosynthesis, Russia) according to equation:

$\mathrm{H}_{2} \mathrm{SeO}_{3}+2 \mathrm{C}_{6} \mathrm{H}_{8} \mathrm{O}_{6} \rightarrow \mathrm{Se}+3 \mathrm{H}_{2} \mathrm{O}+2 \mathrm{C}_{6} \mathrm{H}_{6} \mathrm{O}_{6}$

and leaded to the formation of a zero-valence - selenium sol SeO and dehydroascorbic acid. Sol was unstable in solution and precipitates after 24 hours. In this work, BSA of the culture medium (10\%, BioSera, Brazil) was used as the stabilizer.

The size of nanoparticles were determinated by the photon's cross-correlation method (Nanophox).

\section{Isolation of MSC and coculture with nanoparticles}

Mesenchymal stem cells (MSC) was isolated by enzymatic method. DMEM medium (PanEco, Russia) was used for culture cells, containing fetal bovine serum (FBS, 10\%), and the penicillin-streptomycin solution (1\%, 10000 units of penicillin and streptomycin $(10 \mathrm{mg}$ in $0.9 \% \mathrm{NaCl})$ ) in a humidified atmosphere of $\mathrm{CO} 2(5 \%)$ and air (95\%) at $37{ }^{\circ} \mathrm{C}$. Production of CD34-, CD45-, CD14-, CD20-, CD44+, CD73+, CD90+, CD105+ was proved by flow cytometry. After 5-7 days, the cell culture was more than $80 \%$ confluent, $0.25 \%$ trypsin- $0.02 \%$ EDTA was used for the re-seeding, seeded in a ratio of 1: 2, NP was added on the third passage.

The effect of silver NP was evaluated in cultures with doses of NP 0.004, 0.008, $0.016 \mathrm{mg} / \mathrm{ml}$ from $\mathrm{AgNO}_{3}$ and $\mathrm{Ag}_{2} \mathrm{SO}_{4}$ for 2 weeks. Further experience with silver content of $0.008,0.016,0.024,0.032 \mathrm{mg} / \mathrm{ml}$ was carried out with NP from $\mathrm{AgNO} 3$ also for 2 weeks.

The effect of selenium on MSC was studied according to the scheme: 0.005 and $0.01 \mathrm{mg} / \mathrm{ml} \mathrm{Se} 6000 \mathrm{~nm}$, 0.005 and $0.01 \mathrm{mg} / \mathrm{ml} \mathrm{Se}{ }^{0} 700-1200 \mathrm{~nm}, 0.005$ and $0.01 \mathrm{mg} / \mathrm{ml} \mathrm{Se} \mathrm{e}^{0} 50-1000 \mathrm{~nm}$ during of the week.

\section{Analysis of morphological changes and toxicity}

Morphological evaluation was performed using the method of phase-contrast microscopy using criteria such as the typical/ untypical cell morphology, the presence of apoptotic bodies, and the confluence of the culture. The cytotoxicity assay was performed by using Goryaev's camera with Trypan blue staining. 
The nanoparticles synthesis, exposure them to cultures and analysis were repeated more than 10 times, the results of the counting in Gorjaev's chamber were counted using the Student's ratio $(p=0.05)$ using the Excel Office software.

\section{Results and Discussion}

\section{Silver NP}

Suspensions of 4 species were obtained: $0.001 \%$ of the AgNO3 salt, $0.002 \%$ of the AgNO3 salt, $0.001 \%$ of the Ag2SO4 salt, $0.002 \%$ of the Ag2SO4 salt. The resulting suspensions were analyzed using the cross-correlation method of photons (Nanophox): the suspension contained nanoparticles from 25 to $60 \mathrm{~nm}$, the peak in the distribution curve was in the range of 30 to $50 \mathrm{~nm}$ (Fig. 1).

As a result of the experiment to determine the influence of silver NP depending on the precursors, it was found that low doses of nanoparticles $(0.004 \mathrm{mg} / \mathrm{ml}$, $0.008 \mathrm{mg} / \mathrm{ml}, 0.016 \mathrm{mg} / \mathrm{ml}$ ) from nitrate and silver sulfate salts do not significantly affect on the morphology of the cells for three weeks of cultivation. Explicit differences in the morphology of cells with prolonged exposure of NP obtained from different salts have not been detected.

The control culture of cells without exposure to them by nanoparticles is shown in Fig.2., which reached full confluency on the 14th day of passage (2.1). In the photo, a spindle-like fibroblaste-like cell form (2.2.b.) characteristic of MSC, nuclei with nucleoli (2.2.a.) are clearly visible.

It was possible to establish that increase silver-NP dose caused the decrease of proliferative activity, cell apoptosis becomes more frequent: in Fig. 3. photo of the cell culture after cultivation with $0.032 \mathrm{mg} / \mathrm{ml}$ silver nanoparticles is presented. There was cells in the apoptosis in the culture in Fig. 3 (a), that the changes follows it in their morphology: cell loss of mass, detachment of membranes from plastic, the formation of apoptotic bodies, and, as a result, an increase the debris in culture. Counting cells in Goriayev's chamber confirms that the number of living cells decreases

Fig. 1

Graph of the silvernanoparticles size distribution in suspension

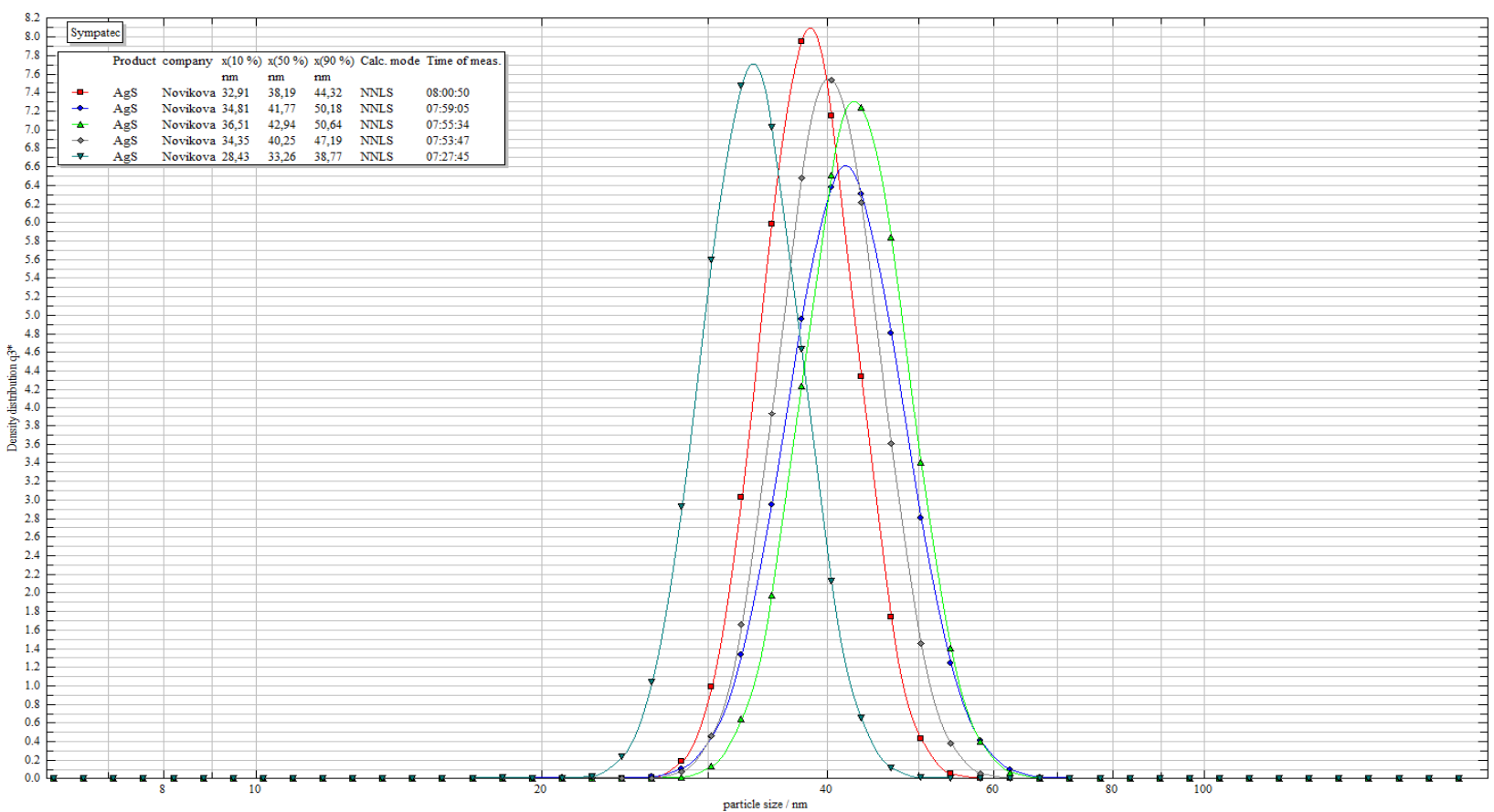




\section{Fig. 2}

Control cell culture low-power and high-power fields: 2.1. 40× magnification general view of the monolayer of cells, 2.2. 400x magnification: a-core and nucleoli, b-cell, c-debris

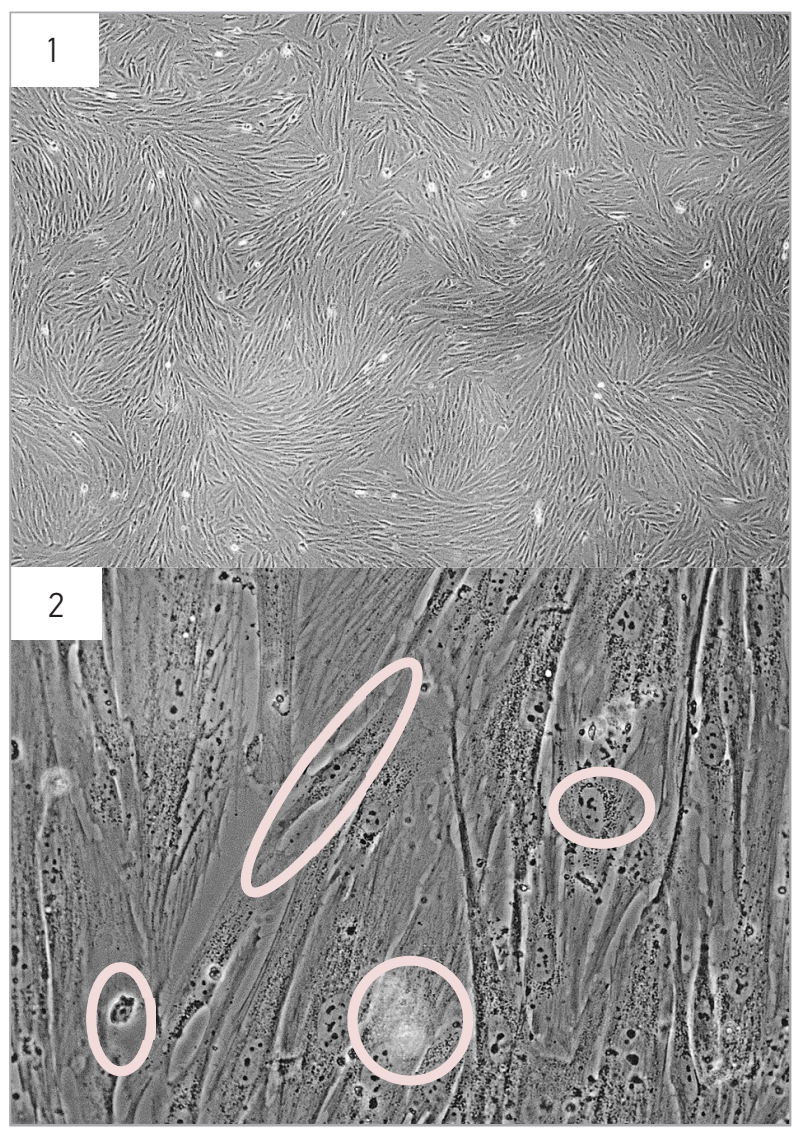

in the culture, the survival rate decreases with an increase in the dose of silver nanoparticles in culture.

Thus, it has been established that silver nanoparticles have a proportional concentration of negative impact on MSCs. There is an oppression of proliferative activity, a change in morphology, apoptotic cells appear.

\section{Selenium NP}

As a result of the production of selenium nanoparticles, the suspension was analyzed by cross-correlation of photons, which showed that the particles reached a size of more than $6000 \mathrm{~nm}$ (Fig. 4D). The suspension obtained after the centrifugation was also analyzed using the cross-correlation method of photons: it contained particles ranging in size from $700 \mathrm{~nm}$ to $1200 \mathrm{~nm}$ (Fig. 4C). After the inclusion of

\section{Fig. 3}

Culture of cells with silver-NP concentrations of $0.032 \mathrm{mg} / \mathrm{ml}$ on

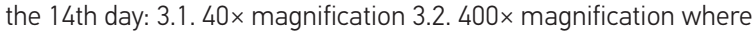
$a$ - cells in the apoptosis stage, $b$ - debris

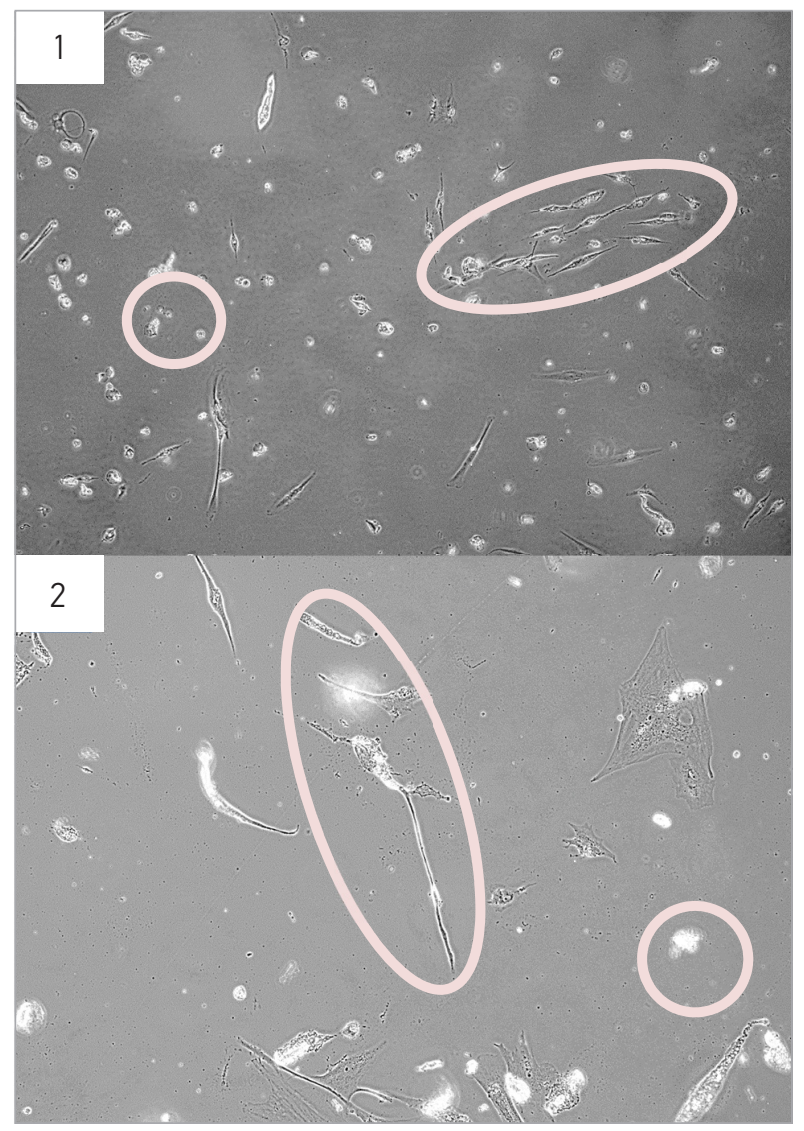

an additional filtration step through a $0.22 \mu \mathrm{m}$ filter, the analysis showed that particles were obtained from $500 \mathrm{~nm}$ to $1000 \mathrm{~nm}$ (Fig. 4B). After further centrifugation and filtration, we obtained NP from 50-100 nm (Fig. 4.A.). Thus, the particles obtained in groups B, C and $D$ was not nanoparticles. But their influence on MSC was still appreciated.

Morphological changes in cell cultures with selenium in groups with NP around 500-1000 nm and 700$1200 \mathrm{~nm}$ caused similar effects: the cells changed their characteristic form (5.a), cell proliferation slowed down, the number of cells decreased, which is indicated by low confluency cultures (Fig.5.) in comparison with the monolayer of the control (Fig.2.), large conglomerates of particles with proteins were found (5.b.). 
Fig. 4

Graph of the selenium nanoparticles size distribution in suspension

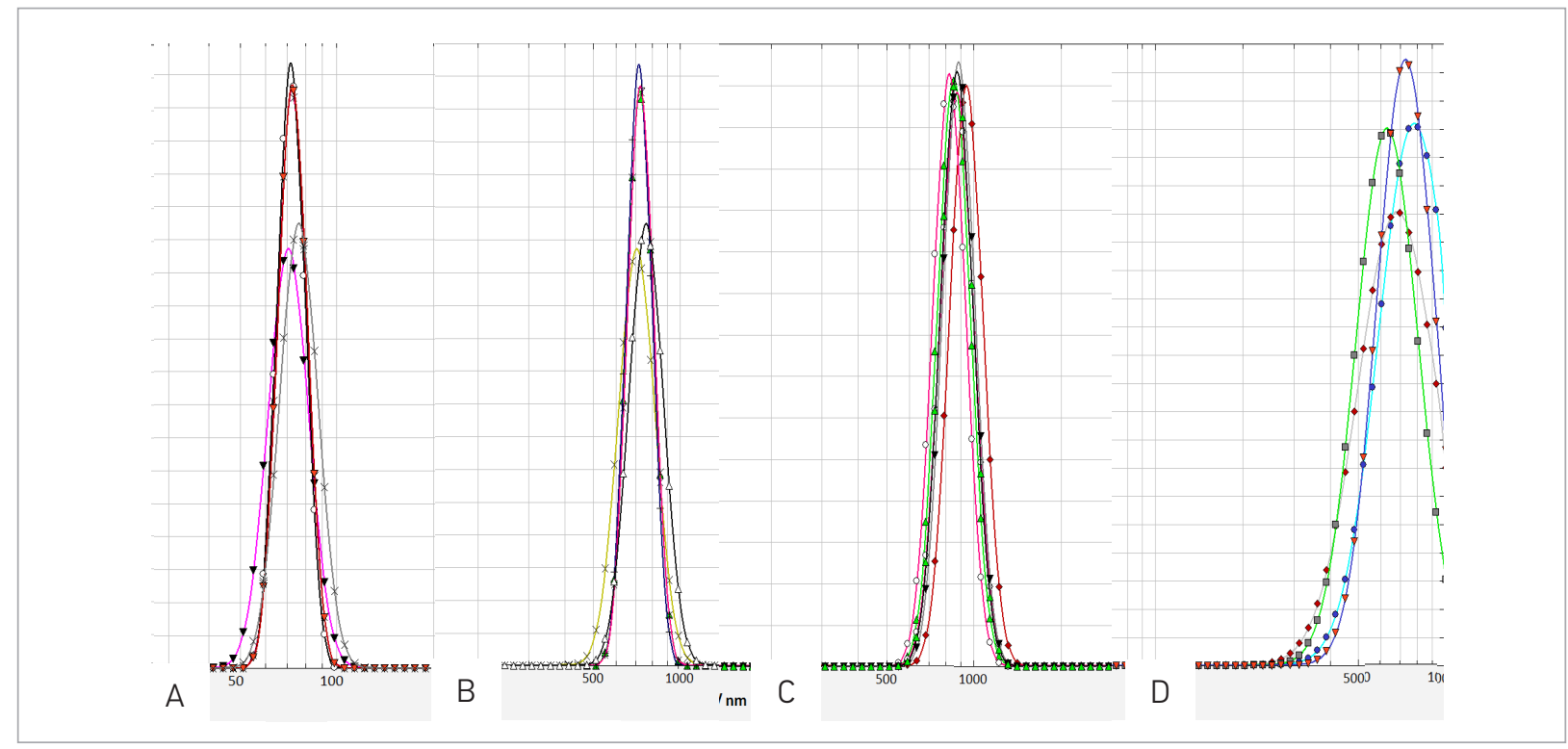

\section{Fig. 5}

Culture of cells with selenium particles with diameters $500-1000 \mathrm{~nm}$ (5.1.) and 700-1200 nm (5.2.); A - the cell, B -conglomerate of particles with proteins, $\mathrm{C}$ - conglomerate of particles $200 \times$ magnification

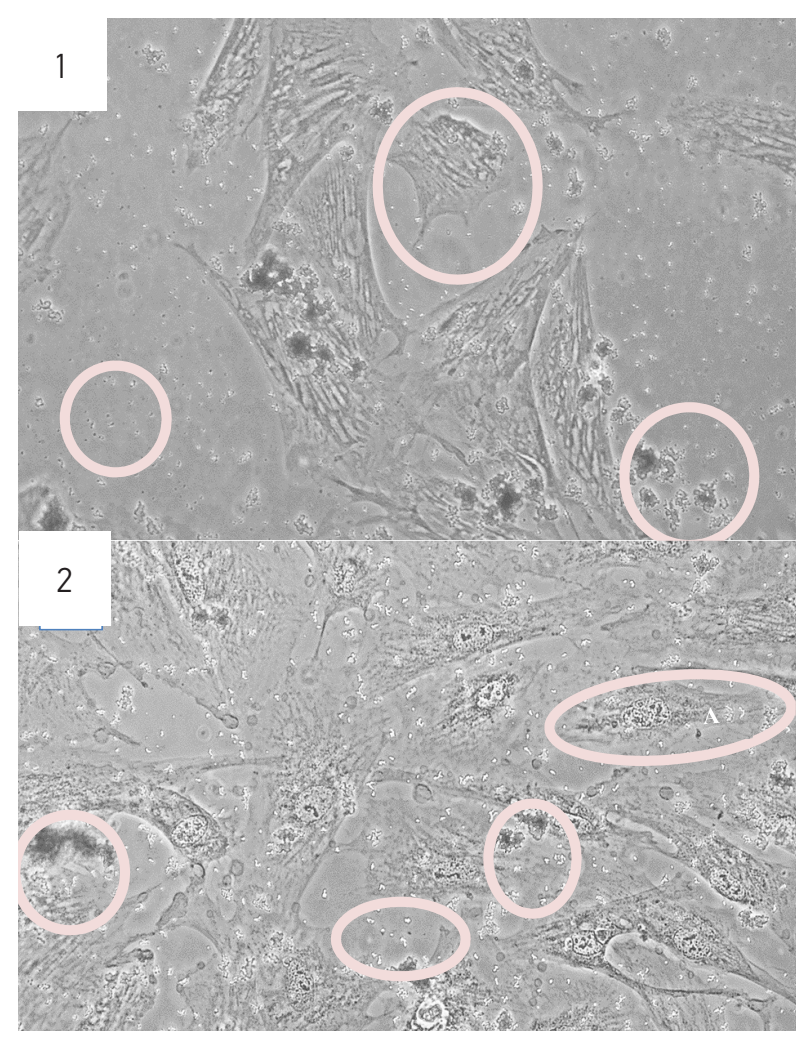

Fig. 6

Cell culture after $30 \mathrm{~min}$ of selenium $6000 \mathrm{~nm}$ exposure: 6.1. 40x magnification, 6.2. 400 × magnification, A - conglomerates of particles with debris, B - apoptotic cell, C - apoptotic vesicles formation

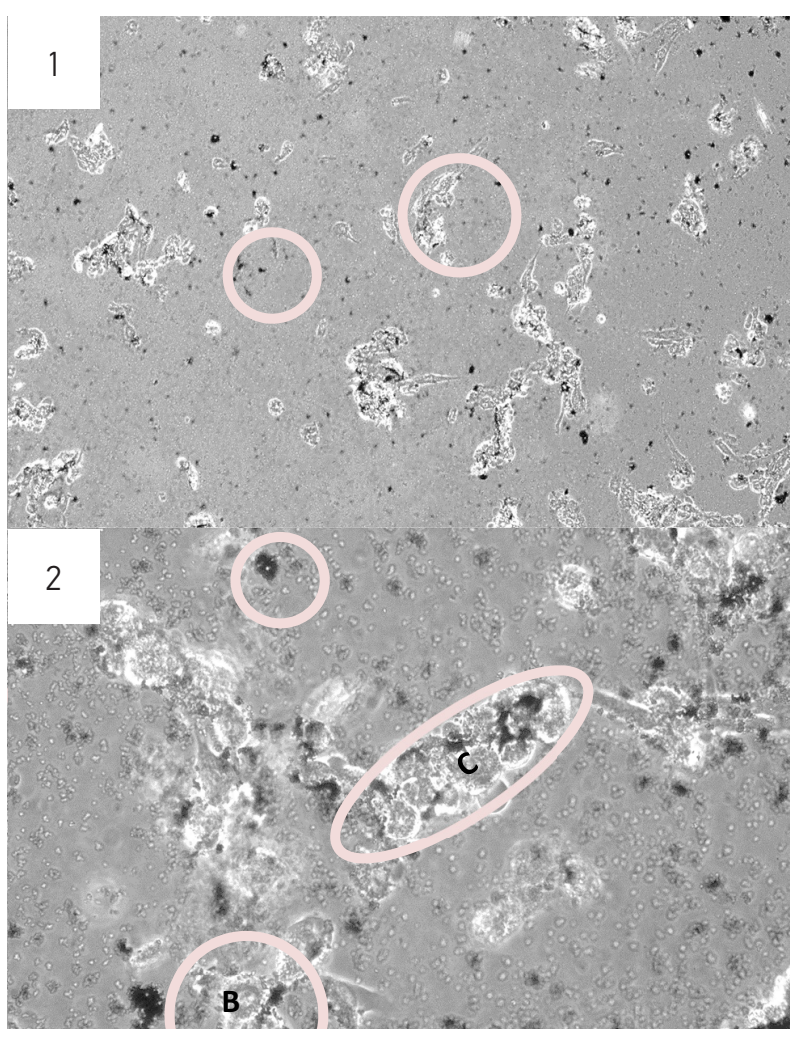


But the groups of cells exposed with selenium particles over $6000 \mathrm{~nm}$ died within half an hour (Fig. 6). In the process of apoptosis (6.a.), the cells were detached from the plastic, formed apototic vesicles (6.c.), All this was accompanied by a conglomeration of particles with proteins and debris (6.b.). This picture was observed regardless of the selected doses of 0.005 and $0.01 \mathrm{mg} / \mathrm{ml}$.

A graph of regularity in the survival of the culture against the particle size and dose was constructed showing that: the percentage of dead cells increases with increasing dose and the percentage of survivors decreases with increasing particle size.

Thus, it has been proved that increase of the selenium particles dose caused morphological changes in MSC, cell differentiation, cell apoptosis. It is proved that increasing particle size increases caused the toxic effect. It was found that selenium particles with a minimum size of $50 \mathrm{~nm}$ and a minimum dose of 0.005

\section{References}

Jones S.A. Controlling wound bioburden with a novel silver-containing Hydrofiber dressing. / S.A. Jones, P.G. Bowler, M. Walker, D. Parsons // Wound Repair Regen. - 2004. - V. 12. - P. 228.

Liu, J., \& Jiang, G. (2015). Silver nanoparticles in the environment. Silver Nanoparticles in the Environment (pp. 1-152). Springer Berlin Heidelberg. https://doi.org/10.1007/978-3662-46070-2

McGillicuddy, E., Murray, I., Kavanagh, S., Morrison, L., Fogarty, A., Cormican, M., ... Morris, D. (2017, January 1). Silver nanoparticles in the environment: Sources, detection and ecotoxicology. Science of the Total Environment. Elsevier B.V. https://doi. org/10.1016/j.scitotenv.2016.10.041

Synthetic And Biogenic Magnetite Nanoparticles For Tracking Of Stem Cells And Dendritic Cells/ Schwarz S., Fernandes F., $\mathrm{mg} / \mathrm{ml}$ caused a toxic effect: a decrease in proliferative activity, few changes in morphology.

\section{Conclusions}

Thus, silver and selenium nanoparticles have a negative effect on mesenchymal stromal cells. From the results obtained, it be assumed that the effect on the entire organism will be negative and it is necessary to create conditions for monitoring and protecting the environment and man from the accumulation of silver and selenium nanoparticles.\{Gurauskiene, 2006, Eco-design methodology for electrical and electronic equipment industry\}

\section{Acknowledgements}

The publication has been prepared with the support of the "RUDN University Program 5-100".

Sanroman L.,/ Journal Of Magnetism And Magnetic Materials. - 2009. - V. 321. - \#10. - P. 1533-1538.

Foldbjerg, R. PVP-coated silver nanoparticles and silver ions induce reactive oxygen species, apoptosis and necrosis in THP-1 monocytes. / R. Foldbjerg, P. Olesen, M. Hougaard, D.A. Dang, H.J. Hoffmann, H. Autrup // Toxicol. Lett. - 2009. - V. 190. - P. 156.

Tran, Q.H. Silver nanoparticles: synthesis, properties, toxicology, applications and perspectives / Q.H. Tran, V.Q. Nguyen, A.-T. Le // Adv. Nat. Sci.: Nanosci. Nanotechnol. - 2013. - N. 4. - P. 386-397.

Tan L.C., Nancharaiah Y.V., van Hullebusch E.D. Selenium: environmental significance, pollution, and biological treatment technologies. Biotechnol Adv. 2016 Sep-Oct;34(5):886-907. Epub 2016 May 25. https://doi.org/10.1016/j.biotechadv.2016.05.005 